\title{
Emergency cervical cerclage and pregnancy outcomes
}

\section{N. Nagendra Prasad, Sherin Annamma Thampan*, R. Nagarathnamma}

Department of Obstetrics and Gynecology, Rajarajeswari Medical College and Hospital, Bengaluru, Karnataka, India.

Received: 01 March 2017

Accepted: 01 April 2017

\section{*Correspondence:}

Dr. Sherin Annamma Thampan,

E-mail: sherinthampan88@gmail.com

Copyright: () the author(s), publisher and licensee Medip Academy. This is an open-access article distributed under the terms of the Creative Commons Attribution Non-Commercial License, which permits unrestricted non-commercial use, distribution, and reproduction in any medium, provided the original work is properly cited.

\section{ABSTRACT}

Background: To evaluate the effectiveness and safety of emergency cervical cerclage in women who presented with advanced cervical changes such as cervical dilatation and bulging foetal membranes.

Methods: This is a retrospective study on all women treated with cervical cerclage presented in the late second trimester with advanced cervical dilatation (2 to $4 \mathrm{cms}$ ) for whom emergency cervical cerclage by McDonald technique.

Results: Out of the 24 patients for whom emergency cervical cerclage was performed, three patients had spontaneous abortion after cervical cerclage, two had PROM and eight of these patients had term delivery. Twenty-one fetus were live born after the period of viability. Nine of these babies were admitted to NICU and 50 percent of the neonates required only regular perinatal care.

Conclusions: Post emergency cervical cerclage, the outcome in terms of prolongation of pregnancy, live births and neonatal survival is better.

Keywords: Cervical dilatation, Emergency cerclage, McDonald

\section{INTRODUCTION}

Cervical incompetence is defined as the inability to support a pregnancy to term due to a functional or structural defect of the cervix. ${ }^{1}$

It is a clinical diagnosis characterized by acute, painless dilatation of the cervix usually in the mid trimester resulting in the prolapse and /or premature rupture of the membranes (PROM) with resultant preterm and often previable delivery. Cervical cerclage has become the mainstay for the management of cervical incompetence.

\section{Cervical anatomy}

Embryologically, the body and cervix of the uterus are derived from the fusion and recanalization of the paramesonephric duct, a process that is complete by the 5 th month of pregnancy.
Histologically, the cervix consists of fibrous connective tissue, muscle, and blood vessels. Muscular connective tissue constitutes approximately $15 \%$ of the cervical stroma, but is not uniformly distributed throughout the cervix, constituting $30 \%$ of the upper third cervix, $18 \%$ of the mid third level and $7 \%$ of the lower third cervix. ${ }^{2}$ Defects in the tensile strength of the fibrous connective are thought to lead to premature cervical dilatation and pregnancy loss.

Over the years shortened cervix became synonymous with incompetent cervix or cervical insufficiency and was an integral part of preterm birth. Preterm birth is the leading cause of perinatal morbidity with survival rates estimated at $54 \%$ at 25 weeks of gestation, $38 \%$ at 24 weeks of gestation and $23 \%$ at 23 weeks of gestation. Cervical insufficiency may be present in up to one percent of the obstetric populations. ${ }^{3,4}$ 


\section{Etiology of cervical incompetence}

Though exact etiology of cervical incompetence is not well understood, the following factors are considered to be contributing to the condition. ${ }^{5-7}$

- Previous cervical trauma such as dilatation and curettage, conization, cauterisation, or amputation

- Abnormal cervical development (including following in- utero exposure to diethyl stibesterol) and connective tissue abnormalities (Ehlers- Danlos syndrome).

- Associated uterine anomalies like unicornuate, bi cornuate or septate uterus.

Past obstetric history usually hints about the possibility of cervical incompetence. On transvaginal scan, cervical shortening, where cervical length is less than $25 \mathrm{~mm}$, with or without funnelling of membranes into the cervical canal diagnoses cervical incompetence. ${ }^{5}$

\section{Management of cervical insufficiency}

Classic cervical incompetence is treated surgically with cerclage which reinforces a weak cervix by a purse string suture.

\section{Indications for cervical cerclage insertion}

- Clinical history or finding of cervical shortening. ${ }^{8}$

- Dilatation of cervix in the absence of uterine contractions

Surgical encerclage can be divided into prophylactic cerclage and therapeutic cerclage

There are 2 procedures implemented in vaginal cervical encerclage.

\section{McDonald cerclage}

Here the cerclage is started with a No. 2 monofilament suture being placed in the body of the cervix very near the level of the internal os. Continuation of suture placement in the body of the cervix so as to encircle the os. As the encirclement is completed, the suture is tightened around the cervical canal sufficiently to reduce the diameter of the canal to 5 to $10 \mathrm{~mm}$, and the suture is tied. The effect of the suture placement on the cervical canal is apparent. A second suture placed somewhat higher may be of value if the first is not in close proximity to the internal os.

\section{Modified shirodhkar cerclage}

A transverse incision is made in the mucosa overlying the anterior cervix, and the bladder is pushed cephalad. A $5 \mathrm{~mm}$ Mersilene tape on a swaged on or Mayo needle is passed anteriorly to posteriorly. The tape is then directed posteriorly to anteriorly on the other side of the cervix. Allis clamps are placed so as to bunch the cervical tissues. This diminishes the distance that the needle must travel submucosally and aids tape placement. The tape is snugly tied anteriorly, after ensuring that all slack has been taken up. The cervical mucosa is then closed with continuous stitches of chromic suture to bury the anterior knot.

\section{Prophylactic trans abdominal cerclage}

Here the suture is placed at the uterine isthmus can be used if there are severe cervical anatomical defects or if there have been prior transvaginal cerclage failures. This can also be considered in patients who have undergone trachelectomy. The placement of an abdominal suture can either be done laparoscopically or open surgical techniques. $^{9-13}$

\section{Emergency cervical cerclage}

Emergency (salvage) cervical cerclage refers to placement of a cerclage in the setting of significant cervical dilatation and/or effacement prior to 28 weeks gestation and in the absence of labor (Figure 1). Emergency encerclage is more difficult to perform.

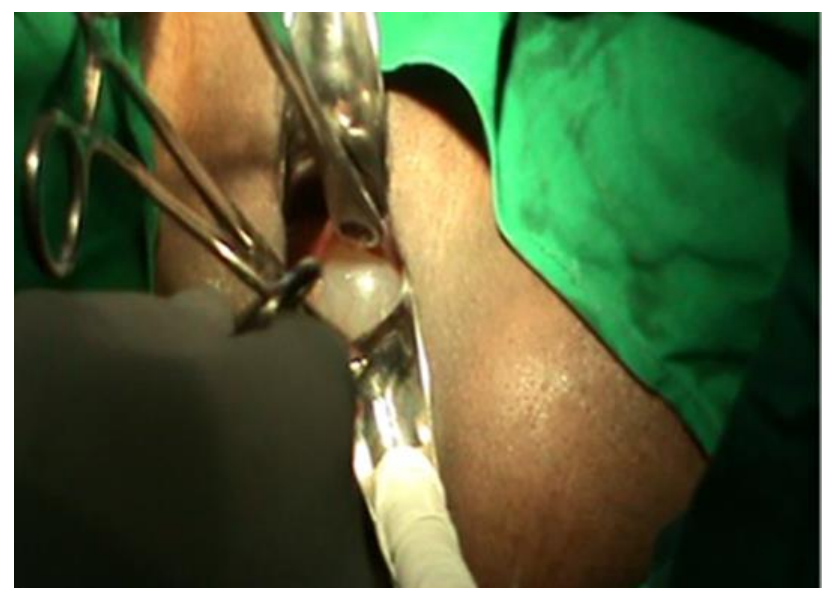

Figure 1: Advanced cervical dilatation where the membranes are visible and bulging.

Replacement of the prolapsed amniotic sac back into the uterus is usually needed to aid suture placement. This is done by tilting the operating table in the head down position along with filling the bladder with $600 \mathrm{ml}$ of saline through an indwelling Foley's catheter. This may reduce the prolapsing membranes, it also helps to carry the cervix cephalad away from the operating field. Another method is to place a Foley's catheter through the cervix and inflating the $30 \mathrm{ml}$ balloon to deflect the amniotic sac cephalad (Figure 2). Cerclage is usually done by Mc Donald technique and the balloon is deflated gradually as the cerclage suture is tightened around the catheter. 


\section{Complications}

The risk and nature of complications is influenced by whether the cerclage is inserted electively or as an emergency with the membranes bulging through the cervix. The risks include sepsis, premature rupture of membranes, premature labour, cervical dystocia (due to cervical scarring), cervical laceration at delivery (up to $11 \%$ ) and haemorrhage.

Membrane rupture during suture placement or within the first 48 hours following surgery is considered by some to be an indication for cerclage removal because of the likelihood of serious foetal or maternal infection.

\section{METHODS}

This is a retrospective study on all women with cervical incompetence and treated with emergency cervical cerclage. The first author was the operating surgeon for all the cases.

All the women who presented between 15 to 26 weeks of gestational age diagnosed with cervical dilatation ranging between 2 to $4 \mathrm{cms}$ were proposed for cervical encerclage after ruling out after ruling out labour, placental abruption and infection.

All the women had the standard preoperative treatment for emergency cervical encerclage according to hospital protocol which included bed rest in trendelenberg position, a broad spectrum antibiotic and parental tocolytics are started for at least 8 hours.

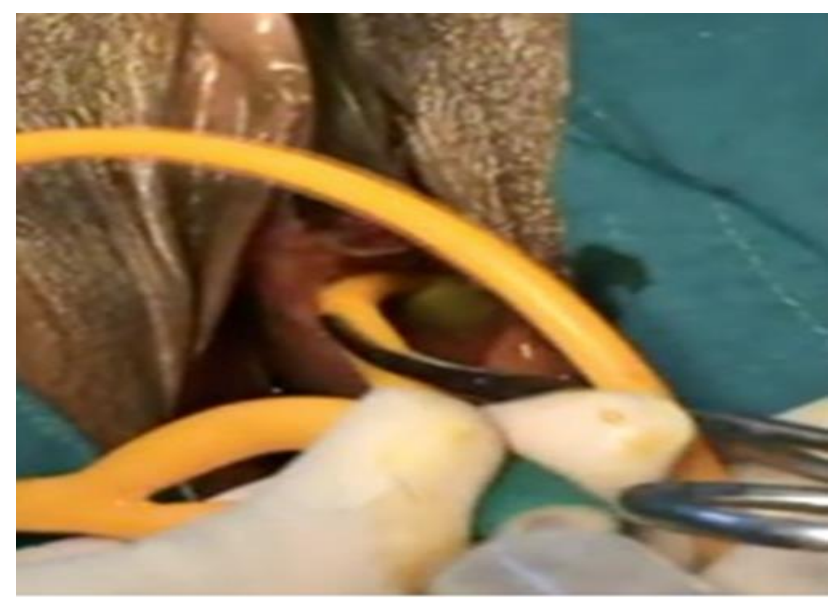

Figure 2: Insertion of Foley's catheter during emergency encerclage to reduce the bulging membranes.

During the operation, general anaesthesia was used, with the patient in head low, lithotomy position. The steep trendelenburg position assisted in spontaneous reduction of the amniotic membranes into the uterine cavity. Furthermore, a Foley's catheter with tip cut up to the balloon is gently inserted into the canal and inflated until the membranes ascend into the uterine cavity (Figure 2 shows the insertion of Foley's catheter to reduce the membranes). Emergency cervical cerclage was then inserted using the McDonald technique with loop polypropylene suture No.1 hitched to atraumatic round body needle.

Postoperatively parenteral tocolytics and antibiotics were continued for $24 \mathrm{hrs}$, the patients were discharged home after 48 hours and continued on antibiotics and oral tocolytics for one week. Following discharge complete bed rest and avoidance of coitus is advised.

All the cerclage sutures were removed electively at the gestation of 37 to 38 weeks of pregnancy or following rupture of fetal membranes, haemorrhage or whenever labour ensued.

\section{RESULTS}

Table 1: Demographic characteristics

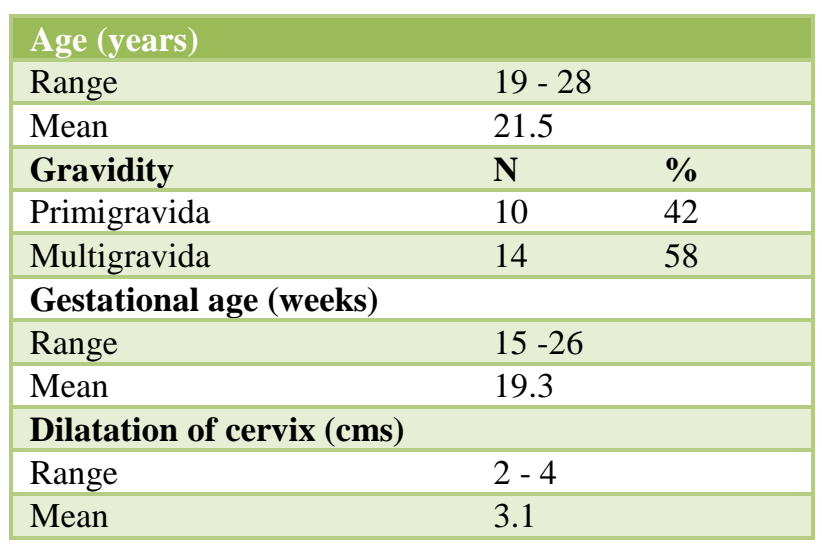

Altogether 24 patients were analysed during the study. The mean age at the time of presentation was 21.5 years with a range of 19 to 28 years. 58 percent of the patients were multigravida and 42 percent were primigravid. The gestational age at which the patients presented with cervical incompetence ranged from 15-26 weeks with a mean of 19.3 weeks. The cervical dilatation at the time of emergency cerclage ranged from $2-4 \mathrm{cms}$ with a mean of $3.1 \mathrm{cms}$.

Table 2: Gestational age at the time of delivery.

\begin{tabular}{|lll|}
\hline Gestational age (weeks) & $\mathbf{N}$ & $\%$ \\
\hline$<28$ & 3 & 12.5 \\
\hline $28-32$ & 8 & 33.3 \\
\hline $33-36$ & 5 & 21 \\
\hline$>36$ & 8 & 33.3 \\
\hline
\end{tabular}

Three patients had spontaneous abortion after cervical cerclage, two had PROM and one had severe contractions not responding to tocolytics and hence cerclage had to be removed. In around 88 percent of the patients pregnancy was prolonged beyond 28 weeks and around 54 percent 
crossed 32 weeks. Eight of these patients had term delivery.

Table 3: Number of weeks pregnancy prolonged after cerclage.

\begin{tabular}{|lll|}
\hline Weeks & N & $\%$ \\
\hline$<5$ & 3 & 12.5 \\
\hline $5 \mathrm{w} 1 \mathrm{~d}-10$ & 4 & 17 \\
\hline $10 \mathrm{w} 1 \mathrm{~d}-15$ & 6 & 25 \\
\hline $15 \mathrm{w} 1 \mathrm{~d}-20$ & 7 & 29 \\
\hline$>20$ & 4 & 17 \\
\hline
\end{tabular}

In our study group majority of the cases, pregnancy was prolonged up to 15 weeks 1 day to 20 weeks $(29 \%)$ followed by 10 to 15 weeks (25\%). In four patients who presented at early gestation with incompetence pregnancy was prolonged beyond 20 weeks.

Table 4: Birth weight at delivery after cerclage.

\begin{tabular}{|lll|}
\hline Birth weight $(\mathrm{kg})$ & $\mathrm{N}$ & $\%$ \\
\hline$<2$ & 12 & 50 \\
\hline $2-2.5$ & 3 & 12.5 \\
\hline $2.51-3$ & 6 & 25 \\
\hline$>3$ & 3 & 12.5 \\
\hline
\end{tabular}

Out of the 24 patients for whom emergency cervical encerclage was performed 21 fetus were live born after the period of viability. The mean birth weight of the neonate was $2.01 \mathrm{~kg}$ with equal number of them weighing more and less than $2 \mathrm{~kg}$. The birth weight ranged between $1.1-3.8 \mathrm{~kg}$.

Table 5: Perinatal outcome after cerclage.

\begin{tabular}{|lll|}
\hline Outcome & N & $\%$ \\
\hline Abortion & 3 & 12.5 \\
\hline NICU admission & 9 & 37.5 \\
\hline No intervention & 12 & 50 \\
\hline
\end{tabular}

After emergency cerclage 50 percent of the neonates required only regular perinatal care and had minimal morbidity. Nine babies were admitted to NICU and interventions ranged from ventilation, surfactant administration to just incubator support with nasal oxygen. The stay in nicu ranged between 3 days to 48 days average being 11.2 days. All the 21 babies were discharged home without any significant sequalae.

Table 6: Morbidity associated with emergency cerclage.

\begin{tabular}{|lll|}
\hline Morbidity & N & $\%$ \\
\hline Abortion & 3 & 12.5 \\
\hline PROM & 6 & 25 \\
\hline Preterm labor & 10 & 42 \\
\hline No complication & 11 & 46 \\
\hline
\end{tabular}

Ten patients had preterm labor of which six of them had uterine anomalies - three with septate uterus, two had bicornuate uterus and one case of unicornuate uterus. Hence in the presence of uterine anomalies in spite of emergency cerclage pregnancy might not be prolonged to term.

Also in the study group 25 percent of the patients had uterine anomalies implying it might be a significant cause for cervical incompetence.

\section{DISCUSSION}

Cervical incompetence is characterized by premature, painless cervical dilatation during gestation in the absence of uterine contractions, followed by expulsion of the preterm foetus. Cervical cerclage is an intervention that is widely used to prevent miscarriage or delivery in the second trimester. Emergency cerclage in the presence of cervical dilatation remains controversial due to its low success rates. Even though the outcomes of these pregnancies are usually poor, but without a cerclage the loss of pregnancy is inevitable.

In our study group, 24 patients underwent emergency cervical cerclage due to cervical dilatation. The mean age of the study group was 21.5 years with a range between 19 to 28 years. There were 10 primigravidas and 14 multigravidas. The demographic characteristics match with the study done by Balasubramanian D et al in 2015, which reported that out of the 7 cases studied majority were primigravidas $(57.4 \%)$ and their average age was 23.3 years (range 20 to 26 years), while their gestational age at the time of encerclage ranged between 22 and 26 weeks (with a mean of 24.1 weeks). ${ }^{14}$

In a study, done with the same objectives by Thaher AJ et al in Riyadh, KSA 14 pregnant women underwent emergency cervical cerclage. ${ }^{15}$ The average GA at the time of cerclage placement was 23 weeks plus 2 days and the average latency to delivery was 7 weeks and 4 days. In our study the gestational age at the time of presentation ranged from 15 to 26 weeks with a mean gestational age of 19.3 weeks. The latency to delivery was almost double at 13.4 weeks probably due to earlier gestational age at which the cerclage was performed.

In another study done by Zhu L Q et al, emergency cerclage led to live-births, with a success rate of $82.28 \% .{ }^{16}$ which is comparable to our study. The mean gestation at delivery was $30.3 \pm 4.7$ weeks (range: $25-39.6$ weeks) and a mean birth weight of $1934.69 \pm 570.37 \mathrm{~g}$ (range: $880-3350 \mathrm{~g}$ ). In our study mean gestational age at delivery was 32.7 weeks (19-40 weeks) and mean birth weight was $2.01 \mathrm{~kg}(0.45-3.8 \mathrm{~kg})$. Both the parameters are comparable and similar and imply that a properly performed emergency cerclage is beneficial in prolonging the gestational age and resulting in live births in more than $80 \%$ of cases. In a study done by A. Ojabo et al in Nigeria, cases were studied and 3 patients underwent 
spontaneous abortions. ${ }^{10}$ This study compared outcome between cervical dilatation that is less than $5 \mathrm{~cm}$ and cervical dilatation that is more than $5 \mathrm{~cm}$, the authors found that cervical cerclage is a better choice if the cervical dilatation at the time of cervical cerclage is less than $5 \mathrm{~cm}$ and that it is of limited use if the dilation is greater than $5 \mathrm{~cm}$. The same study observed that both live birth rate and prolongation of pregnancy is lower if the cervical dilatation is more. However in our study mean dilatation of cervix was $2.97 \mathrm{cms}$ with a range of $2-4 \mathrm{~cm}$. All the three patients who had abortion had a cervical dilatation of $3.5 \mathrm{~cm}$.

Similar to the findings of our study is a study done by Purnima D. et al, Out of the 20 patients in the study group, 12 proceeded to term gestation, 5 went for preterm delivery and 3 resulted in spontaneous miscarriages. ${ }^{18}$

In a study published by L.pereira et al 225 women were included in the trial, after clinical examination showed cervical incompetence. ${ }^{19} 152$ underwent cerclage and 73 were managed expectantly without cerclage. Compared with expectant management, cerclage group was associated with longer latency of gestational age at delivery, improved neonatal survival, birth weight greater than $1.5 \mathrm{~kg}$. Hence rescue cerclage has a definite role when cervical dilatation and bulging membranes complicate the pregnancy.

Other significant observation in our study is 60 percent of post cerclage patients delivering preterm had uterine anomaly. Not much has been reported in the literature about the success of emergency cervical cerclage in presence of uterine anomalies. It might be useful to rule out uterine anomalies in cervical incompetence as it might guide us in counselling about the prognosis even after cervical cerclage.

Use of antibiotics, tocolytics and progesterone has definite role in success of emergency cerclage. Though the surgical technique hasn't changed much over the period of time, improved neonatal outcome can be definitely attributed to better neonatal ICU care and interventions available. In our study the least gestational age at which neonate was salvaged was 28 weeks and birth weight was 870 gms.

\section{CONCLUSION}

The precise incidence of cervical incompetence is unknown. Studies have also shown that where there is mere cervical shortening or funnelling of the cervix as compared to cervical dilatation, the outcome in terms of prolongation of pregnancy and live births and neonatal survival is better.

Over the past decade, several authors have published studies that show a reasonable level of success following emergency cerclage for painless cervical dilatations of up to four $\mathrm{cm}$. There are several reported cases of success with cervical cerclage in preventing mid-trimester pregnancy losses and preterm labour. We recommend that salvage cervical cerclage should be considered in patients with advanced cervical dilatation and bulging membranes in the second trimester. With good neonatal ICU back up most of the pregnancies can be salvaged with minimal morbidity to the neonates.

\section{ACKNOWLEDGMENTS}

The author would like to thank their study group patients for their support and constant follow up to help us fulfil the aim of our study. We are also grateful to the institution to allow access to the necessary records of the concerned patients.

Funding: No funding sources

Conflict of interest: None declared

Ethical approval: The study was approved by the Institutional Ethics Committee

\section{REFERENCES}

1. Norwitz ER, Greene MF, Repke JT. Cervical cerclage - Elective and Emergent ACOG update 1999;24:1-11.

2. Danforth DN. the fibrous nature of the human cervix and its relation to the isthmic segment in the gravid and nongravid uteri. Am J Obstet Gynecol. 1947;53:541-60.

3. Coestole K. Hennessy E. The Epicure study: outcomes to discharge from hospital for infants born at the threshold of viability. Pediatrics. 2000;106:659-71.

4. Rand L, Norwitz. Current controversies in cervical cerclage. Semin Perintol. 2003;27:73-85.

5. Cunningham FG, Kenneth J. William Obstetrics. $24^{\text {th }}$ ed. United States: McGraw-Hill Education. chapter 18, Abortion; 2004:350-370.

6. Cousins L. Cervical cerclage: Patient selection, morbidity, and success rates. Clin Perinatol. 1983:10:321-41.

7. Grimes DA, Schultz KF, Cates WJ. Prevention of uterine perforation during curettage abortion. JAMA. 1984;251:2108-11.

8. Mc Donald IA. Incompetence and cerclage in Denmark 1980-1990. A register based epidemiological survey. Acta Obstet Gynecol. 1978;18:34-7.

9. Hibbard JU, Snow J, Moaward AH. Short cervical length by ultrasound and cerclage. J Perinatol. 2000;(3):161-5.

10. Friedli I, Stamm J, Beguin F. Cerclage by the abdominal route. J Gynecol Obstet Biol Reprod. 1987;(16):951-4.

11. Benson RC, Durfee RB. Trans abdominal cervico uterine cerclage during pregnancy for the treatment of cervical incompetency. Obstet Gynecol. $1965 ;(25): 145-55$. 
12. Lotgering FK, Gaulger IP. Outcome after trans abdominal cervicoisthamic cerclage Obstet Gynecol. 2006;107:779-84.

13. Heath VCF, Souka AP, Erasmur I. Cervical length at 23 weeks of gestation: The value of Shirodhkar suture for the short cervix. Ultrasound Obstet Gynecol. 1998;(12):318-22.

14. Balasubramaniam D, Chithra TV. Outcome of emergency cerclage for advanced cervical dilatation: a retrospective analysis. Inter journal Res Med Sci. 2015;3(1):229-34.

15. Taher A. The Perinatal Outcome in Saudi Women with Emergency Cerclage- a Prospective Study. UTMJ. 2012;90(2):32.

16. Zhu LQ. Pregnancy outcomes of emergency cerclage Medscimonit. 2015;(21):1395-401.

17. Ojabo A, Adesiyun AG, Hembah-Hilekaan SK. Pregnancy Outcomes Following Emergency Cervical
Cerclage. Open Access Library Journal. 20141;1(7):1.

18. Purnima D, Aftab N. Prediction of outcome for Emergency Cervical cerclage in the presence of protruding membranes. ISRN Obstetrics and Gynaecology; 2012:1-4.

19. Cotter PA, Gomez R. Expectant management compare with physical examination indicated cerclage (EM-PEC) in selected woman with a dilated cervix at 140/7-256/7 weeks: results from the EMPEC international cohort study. The American Journal of Obstetrics and Gynaecology. 2007;197(5):483-88.

Cite this article as: Prasad N, Thampan A S, Nagarathnamma R. Emergency cervical cerclage and pregnancy outcomes. Int J Reprod Contracept Obstet Gynecol 2017;6:1993-8. 